OPEN ACCESS

Edited by:

Wen-Jun Li,

Sun Yat-Sen University, China

Reviewed by:

Julie L. Meyer,

University of Florida, USA

Virginia Helena Albarracín,

National Scientific and Technical

Research Council (CONICET),

Argentina

*Correspondence:

Zhiyong Li,

Marine Biotechnology Laboratory,

State Key Laboratory of Microbial

Metabolism, School of Life Sciences and Biotechnology, Shanghai Jiao Tong University, 800 Dongchuan Road, Shanghai 200240, China zyli@situ.edu.cn

Specialty section:

This article was submitted to Extreme Microbiology a section of the journal Frontiers in Microbiology

Received: 23 June 2015 Accepted: 14 September 2015 Published: 01 October 2015

Citation: Sun W, Zhang F, He L, Karthik L and Li Z (2015) Actinomycetes from the South China Sea sponges: isolation, diversity, and potential for aromatic polyketides discovery.

Front. Microbiol. 6:1048.

doi: 10.3389/fmich.2015.01048

\section{Actinomycetes from the South China Sea sponges: isolation, diversity, and potential for aromatic polyketides discovery}

\author{
Wei Sun, Fengli Zhang, Liming He, Loganathan Karthik and Zhiyong Li * \\ Marine Biotechnology Laboratory, State Key Laboratory of Microbial Metabolism, School of Life Sciences and Biotechnology, \\ Shanghai Jiao Tong University, Shanghai, China
}

Marine sponges often harbor dense and diverse microbial communities including actinobacteria. To date no comprehensive investigation has been performed on the culturable diversity of the actinomycetes associated with South China Sea sponges. Structurally novel aromatic polyketides were recently discovered from marine sponge-derived Streptomyces and Saccharopolyspora strains, suggesting that sponge-associated actinomycetes can serve as a new source of aromatic polyketides. In this study, a total of 77 actinomycete strains were isolated from 15 South China Sea sponge species. Phylogenetic characterization of the isolates based on 16S rRNA gene sequencing supported their assignment to 12 families and 20 genera, among which three rare genera (Marihabitans, Polymorphospora, and Streptomonospora) were isolated from marine sponges for the first time. Subsequently, $\beta$-ketoacyl synthase $\left(\mathrm{KS}_{\alpha}\right)$ gene was used as marker for evaluating the potential of the actinomycete strains to produce aromatic polyketides. As a result, $\mathrm{KS}_{\alpha}$ gene was detected in 35 isolates related to seven genera (Kocuria, Micromonospora, Nocardia, Nocardiopsis, Saccharopolyspora, Salinispora, and Streptomyces). Finally, 10 strains were selected for small-scale fermentation, and one angucycline compound was detected from the culture extract of Streptomyces anulatus strain S71. This study advanced our knowledge of the sponge-associated actinomycetes regarding their diversity and potential in producing aromatic polyketides.

Keywords: marine sponges, actinomycetes, diversity, aromatic polyketides, $\mathrm{KS}_{\alpha}$ gene

\section{Introduction}

As one of the oldest multicellular animals (Love et al., 2009), marine sponges (phylum Porifera) often harbor dense and diverse microbial communities, and the sponge-microbe associations represent one of the most complex symbioses on earth (Taylor et al., 2007). Actinobacteria are commonly found in association with sponges (Simister et al., 2012). In the past decade, extensive efforts have been made in isolating actinomycetes from sponges (Zhang et al., 2006; Abdelmohsen et al., 2010, 2014b; Vicente et al., 2013). To date, at least 60 actinobacterial genera have been set apart from marine sponges (Abdelmohsen et al., 2014a). The investigations on the culturable diversity of sponge-associated actinomycetes not only advanced our knowledge of those actinomycetes in 
special habitats but also provided new opportunities for natural product search and discovery (Abdelmohsen et al., 2014a). In China oceans, the largest group of sponges inhabits the South China Sea (Zhang et al., 2003). To our knowledge, in previous studies 15 actinobacterial genera have been isolated from South China Sea sponges (Jiang et al., 2007, 2008; Sun et al., 2010; Li et al., 2011; Xi et al., 2012). Nevertheless, previous cultivation attempts were set to a few South China Sea sponge species out of thousands of South China Sea sponges, which probably underestimated the culturable diversity of sponge-associated actinomycetes. Thus, collecting as many sponges as possible from the South China Sea is significant to comprehensively explore their associated actinomycetes.

Previous surveys have demonstrated that sponges are chemically defended from predation and marine pathogens either by the compounds they produce or those produced by symbionts or associated microorganisms (Puglisi et al., 2014). Actinomycetes are known to produce aromatic polyketides by type II polyketide pathway (Schneider, 2005). Actinomycetederived aromatic polyketide compounds have exhibited a wide range of bioactivities and clinical importance (Hertweck et al., 2007). Notably, a few anthracyclines and tetracyclines have emerged as clinical drugs for decades, such as doxorubicin (antineoplastic) and tetracycline (antibiotic). Furthermore, many of these compounds are promising drug candidates (Hertweck et al., 2007). Therefore, sponge-associated actinomycetes may provide chemical defense for their hosts by producing aromatic polyketides. Recently, in exploring new sources of aromatic polyketides the sponge-associated actinomycetes warranted particular attention. Particularly, a few structurally novel aromatic polyketides were discovered from spongeassociated actinomycetes such as Saccharopolyspora and Streptomyces strains (Perez et al., 2009; Motohashi et al., 2010; Schneemann et al., 2010a). In view of the remarkable diversity of sponge-associated actinomycetes, the producers of aromatic polyketides are not merely limited to Saccharopolyspora and Streptomyces. Thus, we opine that the potential of sponge-associated actinomycetes in producing aromatic polyketides is underexplored and it is worth investigating in depth.

Over the past decade, sequence-guided genetic screening strategy has been used in the discovery of certain compound classes from actinomycetes, such as halometabolites (Hornung et al., 2007), type I polyketides (Gontang et al., 2010), and phenazines (Karuppiah et al., 2015), indicating that a small amount of sequence from appropriate genetic loci can be used to predict secondary-metabolite production in cases where the sequences have high identity level to experimentally characterized biosynthetic pathways. The genecompound route has become a feasible approach for natural product search and discovery. Therefore, genetic screening strategy together with small-scale fermentation and chemical analyses was used in this study to specifically search for aromatic polyketides.

In this work, we aimed to investigate the culturable diversity of sponge-associated actinomycetes from the South China Sea and explore the potential use of the sponge-associated actinomycetes as a novel source of aromatic polyketides. As a result, we cultivated as many as 20 actinomycete genera, screened seven genera as potential producers of aromatic polyketides and identified one angucycline compound from a Streptomyces strain. This study advanced our knowledge of South China Sea sponge-associated actinomycetes in respect to their diversity and metabolic potential of aromatic polyketides.

\section{Materials and Methods}

\section{Sample Collection}

A total of 15 sponge species were collected by scuba diving from the South China Sea, including six at a depth of 5$10 \mathrm{~m}$ from coastal waters, respectively Sanya Bay $\left(18^{\circ} 13^{\prime} \mathrm{N}\right.$; $\left.109^{\circ} 29^{\prime} \mathrm{E}\right)$, Xinying Harbor $\left(19^{\circ} 90^{\prime} \mathrm{N} ; 109^{\circ} 52^{\prime} \mathrm{E}\right)$, and Xincun Harbor $\left(18^{\circ} 40^{\prime} \mathrm{N} ; 110^{\circ} 00^{\prime} \mathrm{E}\right)$ and nine at a depth of $10-20 \mathrm{~m}$ from a remote island, Yongxing Island $\left(16^{\circ} 50^{\prime} \mathrm{N} ; 112^{\circ} 20^{\prime} \mathrm{E}\right)$ (Table 1). The sponges were identified based on their morphology or $18 \mathrm{~S}$ rRNA gene/internal transcribed spacer (ITS) sequences (Table 1). The samples were placed into plastic bags and transported to the laboratory using ice box, then stored at $z-20^{\circ} \mathrm{C}$ until analysis.

\section{Isolation of Actinomycetes}

Five media were used for the isolation of sponge-associated actinomycetes (Table S1), four of which were chosen based on previous studies on the culturable diversity of marine sedimentderived and sponge-associated actinomycetes (Mincer et al., 2002; Zhang et al., 2006; Abdelmohsen et al., 2010) and one was designed in this study. All media were supplemented with $\mathrm{K}_{2} \mathrm{Cr}_{2} \mathrm{O}_{7}\left(50 \mu \mathrm{gml}^{-1}\right)$ to inhibit fungi and nalidixic acid $\left(15 \mu \mathrm{gml}^{-1}\right)$ to inhibit Gram-negative bacteria. Sponge samples were rinsed with sterile artificial seawater $(26.52 \mathrm{~g}$ $\mathrm{NaCl}, 5.228 \mathrm{~g} \mathrm{MgCl}_{2} 6 \mathrm{H}_{2} \mathrm{O}, 3.305 \mathrm{~g} \mathrm{MgSO}_{4}, 1.141 \mathrm{~g} \mathrm{CaCl}_{2}$, $0.725 \mathrm{~g} \mathrm{KCl}, 0.202 \mathrm{~g} \mathrm{NaHCO}, 0.083 \mathrm{~g} \mathrm{NaBr}, 1 \mathrm{~L}$ distilled water) to remove the microbes loosely attached on the surface. Subsequently, a few tissue cubes were excised from different sections (including cortex and endosome) of the sponge samples. They were cut into pieces and aseptically ground using sterilized pestles and mortars. Actinomycetes were isolated by means of serial dilution and plating techniques. The inoculated plates were incubated at $28^{\circ} \mathrm{C}$ for 3-6 weeks. The colonies bearing distinct morphological characteristics were picked up and transferred onto freshly prepared media until pure cultures were obtained.

\section{Genomic DNA Extraction}

To prepare cultures for the extraction of genomic DNA from the isolates, a single colony was transferred to a $5 \mathrm{ml}$ microtube with $1 \mathrm{ml}$ of liquid medium from which the isolate was originally picked up. The cultures were incubated for $3-5$ days at $28^{\circ} \mathrm{C}$ with shaking at $180 \mathrm{rpm}$. Bacterial cells from these cultures were collected by centrifugation and genomic DNA was extracted as described by Sun et al. (2010).

\section{PCR Amplification and Sequencing of 16S rDNA}

The Actinobacteria-specific primers S-C-Act-0235-a-S-20 (5'CGCGGCCTATCAGCTTGTTG-3') and S-C-Act-0878-a-A-19 
TABLE 1 | Sponge samples collected from the South China Sea and their actinomycete isolates.

\begin{tabular}{|c|c|c|c|c|c|}
\hline Sponge species & Identification method (NCBI accession no.) & Geographical location & Collection month & No. of isolates & No. of genera \\
\hline Haliclona sp. & morphology & Sanya Bay & 2009.07 & 11 & 6 \\
\hline Trachycladus laevispirulifer & morphology & Xinying Harbor & 2010.06 & 3 & 3 \\
\hline Amphimedon queenslandica & ITS sequence (KC762728) & Xincun Harbor & 2011.05 & 6 & 3 \\
\hline Haliclona mediterranea & 18S rRNA gene sequence (KC762723) & Xincun Harbor & 2011.05 & 3 & 2 \\
\hline Lamellodysidea sp. & ITS sequence (KC762730) & Xincun Harbor & 2011.05 & 8 & 5 \\
\hline Cliona sp. & ITS sequence (KC762729) & Xincun Harbor & 2011.05 & 5 & 2 \\
\hline Phyllospongia foliascens & morphology & Yongxing Island & 2011.05 & 1 & 1 \\
\hline Agelas clathrodes & 18S rRNA gene sequence (KC762715) & Yongxing Island & 2011.05 & 2 & 2 \\
\hline Ircinia felix & 18S rRNA gene sequence (KC762716) & Yongxing Island & 2011.05 & 2 & 2 \\
\hline Hippospongia lachne & 18S rRNA gene sequence (KC762719) & Yongxing Island & 2011.05 & 2 & 1 \\
\hline Cinachyrella sp. & 18S rRNA gene sequence (KC762720) & Yongxing Island & 2011.05 & 5 & 4 \\
\hline Aplysina fistularis & 18S rRNA gene sequence (KC762723) & Yongxing Island & 2011.05 & 8 & 2 \\
\hline Arenosclera heroni & 18S rRNA gene sequence (KJ675584) & Yongxing Island & 2013.07 & 5 & 4 \\
\hline Plakortis simplex & morphology & Yongxing Island & 2013.07 & 12 & 4 \\
\hline Phakellia fusca & morphology & Yongxing Island & 2013.07 & 4 & 3 \\
\hline
\end{tabular}

(5'-CCGTACTCCCCAGGCGGGG-3') were used for the amplification of actinobacterial 16S rRNA gene fragment (Stach et al., 2003). Cycling conditions were as follows: initial denaturation at $95^{\circ} \mathrm{C}$ for $4 \mathrm{~min}, 30$ cycles of $95^{\circ} \mathrm{C}$ for $45 \mathrm{~s}, 68^{\circ} \mathrm{C}$ for $45 \mathrm{~s}$, and $72^{\circ} \mathrm{C}$ for $1 \mathrm{~min}$, and a final extension of $5 \mathrm{~min}$ at $72^{\circ} \mathrm{C}$. Subsequently, the universal bacterial primers $27 \mathrm{~F}\left(5^{\prime}-\mathrm{GAG}\right.$ TTTGATCCTGGCTCAG-3') and 1500R (5'-AGAAAGGAG GTGATCCAGCC-3') were used to amplify nearly complete $16 \mathrm{~S}$ rRNA gene of the actinomycete candidates (Woese et al., 1983). Cycling conditions were as follows: initial denaturation at $95^{\circ} \mathrm{C}$ for $3 \mathrm{~min}, 30$ cycles of $94^{\circ} \mathrm{C}$ for $30 \mathrm{~s}, 54^{\circ} \mathrm{C}$ for $40 \mathrm{~s}$, and $72^{\circ} \mathrm{C}$ for $2 \mathrm{~min}$, and a final extension of $10 \mathrm{~min}$ at $72^{\circ} \mathrm{C}$. The PCR products were purified and sequenced on the ABI 3730 automated sequencer at Majorbio Bio-Pharm Technology Co. Ltd. (Shanghai).

\section{PCR Amplification, Cloning, and Sequencing of KS Gene}

To screen aromatic polyketide producers from all the isolates, the degenerate primers IIPF6 (5'-TSGCSTGCTTCGAYGCSATC-3') and IIPR6 (5' ${ }^{\prime}$ TGGAANCCGCCGAABCCGCT-3') were used to amplify type II polyketide $\mathrm{KS}_{\alpha}$ gene fragment (Metsä-Ketelä et al., 1999). This primer pair was reported to be favorable for the majority of known $\mathrm{KS}_{\alpha}$ gene and previously used in the investigation on marine sponge-associated actinobacteria (Schneemann et al., 2010b). Cycling conditions were as follows: initial denaturation at $95^{\circ} \mathrm{C}$ for $5 \mathrm{~min}, 30$ cycles of $95^{\circ} \mathrm{C}$ for $35 \mathrm{~s}, 55^{\circ} \mathrm{C}$ for $40 \mathrm{~s}$, and $72^{\circ} \mathrm{C}$ for $1 \mathrm{~min}$, and a final extension of $10 \mathrm{~min}$ at $72^{\circ} \mathrm{C}$. The amplified products of approximately 600 bp were recovered and purified using Agarose Gel DNA Purification Kit (Takara, Dalian). Purified PCR products were cloned into pMD18-T vector (Takara, Dalian) and transformed into $\mathrm{CaCl}_{2}$-competent Escherichia coli $\mathrm{DH} 5 \alpha$. The positive recombinants were screened on X-Gal-IPTG-ampicillin plates. Respectively five positive clones were randomly selected from each library and sequenced using M13F primer on the
ABI 3730 automated sequencer at Sangon Biotech Co. Ltd. (Shanghai).

\section{Sequence Analysis}

All the sequence data were proofread using Chromas, version 1.62 (Technelysium). The 16S rRNA gene sequences were compared with those from the type strains available in NCBI (http://www.ncbi.nlm.nih.gov/) using the Basic Local Alignment Search Tool (BLAST) (Altschul et al., 1990). For $\mathrm{KS}_{\alpha}$ gene analysis, the nucleotide sequences were translated to amino acid sequences using the web tool ORF Finder in NCBI (http:// www.ncbi.nlm.nih.gov/projects/gorf/). The deduced amino acid sequences were compared with the $\mathrm{KS}_{\alpha}$ sequences in PKMiner database (http://www.webcitation.org/6C9a5WoFY) using the type II PKS domain classifiers (Kim and Yi, 2012). The top matches were derived from the $\mathrm{KS}_{\alpha}$ sequences associated with 42 experimentally characterized pathways. For phylogenetic analysis, multiple sequence alignment was performed using CLUSTALX, version 1.81. Phylogenetic tree was constructed using Mega 4.1 (Tamura et al., 2007). The consistency of the trees was verified by bootstrapping (1000 replicates) for parsimony.

\section{Small-scale Fermentation}

To test the production of aromatic polyketides, small-scale fermentation studies were performed targeting 10 representative strains, which were selected based on $\mathrm{KS}_{\alpha}$ sequence analyses. They were grown in $250 \mathrm{ml}$ Erlenmeyer flasks each containing $100 \mathrm{ml}$ of medium GYM4 (10 g glucose, $4 \mathrm{~g}$ yeast extract, $4 \mathrm{~g}$ malt extract, 1 liter water, $\mathrm{pH}$ 7.2) for 5 days at $28^{\circ} \mathrm{C}$ with shaking (at $120 \mathrm{rpm}$ ) in the dark. Each culture was inoculated separately with a $1 \mathrm{~cm}^{2}$ piece from a culture grown on a GYM4 agar plate for 2 weeks at $28^{\circ} \mathrm{C}$ in the dark.

\section{Chemical Analysis of Culture Extracts}

After mycelium was removed by vacuum filtration, the fermentation broth was extracted with $100 \mathrm{ml}$ of acetic ether 
(EtOAc) and taken to dryness by rotary evaporation. EtOAc extract was dissolved in methanol for HPLC-DAD analysis on an Agilent 1200 series (Agilent Technologies, USA) with an Diode Array Detector (DAD) and a C18 RP-column (Eclipse XDBC18 $5 \mu \mathrm{m}, 4.6 \times 150 \mathrm{~mm}$ ), with a gradient from $5 \%$ acetonitrile in water to $100 \%$ acetonitrile over $20 \mathrm{~min}$. Ultraviolet-visible (UV-vis) absorption spectra ranging from 200 to $600 \mathrm{~nm}$ of the components in each crude extract were examined. Compounds owning characteristic UV-vis absorption of aromatic polyketides were searched and designated as putative candidates. Prior to LC/MS analysis, the compound candidates were preliminarily separated from the crude extracts by semi-preparative HPLC with methanol gradient elution. This procedure was conducted on an Agilent 1200 series (Agilent Technologies, USA) with a variable wavelength detector (VWD) and a C18 RP-column (Unitary C18 $5 \mu \mathrm{m}, 10 \times 250 \mathrm{~mm}$ ).

Collected fractions were dried in vacuo and dissolved in methanol for LC/MS analysis. The fractions were detected on an ultra-performance liquid chromatography and quadrupole time of flight mass spectroscopy (UPLC-QTOF-MS Premier, Waters Corporation, USA). The analytes were separated on a C18 RP-column (ACQUITY BEH-C18 $1.7 \mu \mathrm{m}, 2.1 \times$ $100 \mathrm{~mm}$, Waters Co.) with methanol gradient elution. Highresolution mass spectrum (HR-MS) of target ion was acquired in positive electro-spray ionization mass spectrum (ESI-MS) mode.

MS data was analyzed using the software MassLynx. The major ion peaks with a mass range of 300-1000 Da were preferentially selected. Corresponding to each peak $\left([\mathrm{M}+\mathrm{H}]^{+}\right.$or $\left.[\mathrm{M}+\mathrm{Na}]^{+}\right)$, a few suggested molecular formula were obtained. After those not matching aromatic polyketide compounds were excluded, the remaining ones were used as queries (subtracting one $\mathrm{H}$ or $\mathrm{Na}$ ) to match reported aromatic polyketides in SciFinder database (https://scifinder.cas.org/scifinder/). For those retrieved compounds, their UV-vis absorption spectra were compared with our target substance.

\section{Nucleotide Sequence Accession Numbers}

The sequences obtained in this study were deposited to GenBank with the 16S rRNA gene sequences under the accession numbers: JX007945-JX008000, KJ094386-KJ094406 and the $\mathrm{KS}_{\alpha}$ gene sequences under the numbers: JX008002-JX008015, KJ094407KJ094410.

\section{Results}

\section{Culture-dependent Diversity of Sponge-associated Actinomycetes}

In this study, a total of 77 isolates were identified as actinomycetes, which were assigned to 12 families and 20 genera (Table 2). Among the 20 genera, Micromonospora, Mycobacterium, Nocardia, Nocardiopsis, Pseudonocardia, Rhodococcus, Salinispora, and Streptomyces were previously isolated from South China Sea sponges (Jiang et al., 2007, 2008; Sun et al., 2010; Li et al., 2011; Xi et al., 2012), the other 12 genera marked in Table 2 were cultivated from South China Sea sponges first time. Based on the latest reviews (Abdelmohsen et al., 2014a; Valliappan et al., 2014) and our retrievals of sponge-derived 16S rRNA gene sequences in GenBank, we found this was the first report of three rare genera, i.e., Marihabitans, Polymorphospora, and Streptomonospora, isolated from marine sponges.

The highest number of the isolates was affiliated with Salinispora, followed by Streptomyces, Kocuria, Serinicoccus, Micromonospora, Nocardiopsis, Polymorphospora, and other genera (Figure 1A). The number of the isolates differed considerably among different marine sponges. Plakortis simplex yielded the highest number of isolates, followed by Haliclona sp., Lamellodysidea sp., Aplysina fistularis, Amphimedon queenslandica, and other sponges (Table 1). Similarly, the actinobacterial diversity at the genus level also varied as sponge species. The highest diversity was observed in Haliclona sp. with six genera cultivated, followed by Lamellodysidea sp. and other sponges (Table 1). The 77 isolates were assigned to 40 operational taxonomic units (OTUs) based on 99.5\% sequence identity, representing 40 species. The most diverse group was Streptomyces with 14 OTUs obtained, followed by Kocuria and other genera (Figure 1B).

On the whole, Streptomyces and Salinispora were most common groups in the South China Sea sponges. The former was isolated from nine sponges and the latter from six sponges. Streptomyces was widespread in the sponges from distinct geographical locations whereas Salinispora was mainly distributed in the open sea sponges. Additionally, Kocuria was derived from four sponges inhabiting the same site, Xincun Harbor, indicating its distribution specificity.

\section{Structure Diversity Evaluation of Putative Aromatic Polyketide Products}

PCR fragments of $\mathrm{KS}_{\alpha}$ gene were amplified from 35 out of 77 isolates (Table 2). The 35 isolates were assigned to 17 OTUs. In total, 17 PCR fragments from 17 OTUs were selected for $\mathrm{KS}_{\alpha}$ gene cloning and sequencing, and 18 unique sequences were obtained. Based on homology comparison (Table 3) and phylogenetic analysis (Figure 2), high structural diversity of putative aromatic polyketide products was observed, concerning different subtypes. Homology-based searches on the amino acid level indicated that the putative $\mathrm{KS}_{\alpha}$ sequences, respectively displayed $85.2-100 \%$ maximum similarity to those KSs associated with experimentally characterized biosynthetic pathways (Table 3). By comparing those known $\mathrm{KS}_{\alpha}$ sequences in PKMiner database, it was observed that most sequences grouped in the same subtype share $\geq 93.6 \%$ amino acid similarity with each other. Thus, this similarity was used as sequence clustering criterion in this work. Of the obtained $18 \mathrm{KS}_{\alpha}$ sequences, eight shared $\geq 93.6 \%$ similarity with their top matches, which were derived from six Streptomyces strains, one Micromonospora, and one Nocardia strain. The matches for these eight sequences were to KSs responsible for the biosynthesis of three subgroups, respectively benzoisochromanequinones, angucyclines, and pentangular polyphenols. Specifically, one strain (S97) corresponded to benzoisochromanequinone subtype, three strains (S41, S71, and S107) were linked with angucycline subclass and four 
TABLE 2 | Molecular identification of the actinomycetes from South China Sea sponges based on 16S rRNA gene and $\mathrm{KS}_{\alpha}$ gene detection.

\begin{tabular}{|c|c|c|c|c|c|c|}
\hline Family & Genus & OUT no. & Strain (NCBI accession no.) & Nearest type strain (NCBI accession no.) & Identity (\%) & PKS II \\
\hline \multirow[t]{3}{*}{ Intrasporangiaceae } & Marihabitans* & 3 & S53 (JX007977) & M. asiaticum (NR_041559) & 100 & - \\
\hline & Serinicoccus* & 4 & S11 (JX007953) & S. chungangensis (HM068886) & 98.7 & - \\
\hline & & 4 & S69 (JX007986) & S. chungangensis (HM068886) & 98.6 & - \\
\hline \multirow[t]{2}{*}{ Microbacteriaceae } & Microbacterium ${ }^{*}$ & 5 & S15 (JX007956) & M. chocolatum (AM181503) & 99.8 & - \\
\hline & & 5 & S25 (JX007959) & M. chocolatum (AM181503) & 99.9 & - \\
\hline \multirow[t]{8}{*}{ Micrococcaceae } & Arthrobacter ${ }^{*}$ & 6 & S70 (JX007987) & A. protophormiae (NR_026195) & 99.8 & - \\
\hline & & 8 & S50 (JX007975) & K. turfanensis (NR_043899) & 98.7 & - \\
\hline & & 8 & S61 (JX007984) & K. turfanensis (NR_043899) & 98.7 & - \\
\hline & & 9 & S43 (JX007971) & K. flava (NR_044308) & 99.7 & - \\
\hline & & 10 & S45 (JX007972) & K. palustris (NR_026451) & 100 & - \\
\hline & & 10 & S62 (JX007985) & K. palustris (NR_026451) & 99.9 & - \\
\hline & & 11 & S48 (JX007973) & K. marina (NR_025723) & 99.7 & - \\
\hline & Micrococcus* & 12 & S23 (JX007957) & M. endophyticus (NR_044365) & 99.8 & - \\
\hline \multirow[t]{21}{*}{ Micromonosporaceae } & Micromonospora & 13 & S60 (JX007983) & M. aurantiaca (NR_074415) & 99.6 & - \\
\hline & & 13 & S80 (JX007997) & M. aurantiaca (NR_074415) & 99.5 & - \\
\hline & & 13 & S97\# (KJ094396) & M. aurantiaca (NR_074415) & 99.4 & + \\
\hline & & 16 & S55 (JX007979) & S. arenicola (NR_074612) & 99.9 & + \\
\hline & & 16 & S56 (JX007980) & S. arenicola (NR_074612) & 99.9 & + \\
\hline & & 16 & S58 (JX007981) & S. arenicola (NR_074612) & 99.9 & + \\
\hline & & 16 & S83 (JX008000) & S. arenicola (NR_074612) & 100 & + \\
\hline & & 16 & S84 (KJ094386) & S. arenicola (NR_074612) & 100 & + \\
\hline & & 16 & S87 (KJ094389) & S. arenicola (NR_074612) & 99.9 & + \\
\hline & & 16 & S93 (KJ094392) & S. arenicola (NR_074612) & 99.8 & + \\
\hline & & 16 & S94 (KJ094393) & S. arenicola (NR_074612) & 100 & + \\
\hline & & 16 & S99 (KJ094398) & S. arenicola (NR_074612) & 99.9 & + \\
\hline & & 16 & S100 (KJ094399) & S. arenicola (NR_074612) & 100 & + \\
\hline & & 16 & S102 (KJ094401) & S. arenicola (NR_074612) & 99.9 & + \\
\hline & & 16 & S108 (KJ094405) & S. arenicola (NR_074612) & 100 & + \\
\hline & & 17 & S34\# (JX007964) & S. tropica (NR_074502) & 99.5 & + \\
\hline & & 17 & S54 (JX007978) & S. tropica (NR_074502) & 99.5 & - \\
\hline & & 17 & S96 (KJ094395) & S. tropica (NR_074502) & 99.5 & - \\
\hline & & 17 & S98 (KJ094397) & S. tropica (NR_074502) & 99.4 & - \\
\hline & & 17 & S101 (KJ094400) & S. tropica (NR_074502) & 99.5 & - \\
\hline & & 17 & S103 (KJ094402) & S. tropica (NR_074502) & 99.4 & - \\
\hline
\end{tabular}


TABLE 2 | Continued

\begin{tabular}{|c|c|c|c|c|c|c|}
\hline Family & Genus & OUT no. & Strain (NCBI accession no.) & Nearest type strain (NCBI accession no.) & Identity (\%) & PKS II \\
\hline \multirow[t]{2}{*}{ Mycobacteriaceae } & Mycobacterium & 18 & S01 (JX007945) & M. poriferae (NR_025235) & 98.9 & - \\
\hline & & 18 & S02 (JX007946) & M. poriferae (NR_025235) & 98.9 & - \\
\hline \multirow[t]{3}{*}{ Nocardiaceae } & Nocardia & 19 & S107\# (KJ094404) & N. araoensis (NR_028652) & 98.6 & + \\
\hline & Rhodococcus & 20 & S106 (KJ094403) & R. opacus(NR_074632) & 98.2 & - \\
\hline & & 20 & S109 (KJ094406) & R. opacus(NR_074632) & 98.0 & - \\
\hline \multirow[t]{4}{*}{ Nocardiopsaceae } & Nocardiopsis & 21 & S77 (JX007994) & N. alba (NR_026340) & 100 & + \\
\hline & & 21 & S78\# (JX007995) & N. alba (NR_026340) & 99.9 & + \\
\hline & & 22 & S92\# (KJ094391) & N. halotolerans (NR_025422) & 99.1 & + \\
\hline & Streptomonospora* & 23 & S05 (JX007947) & S. halophila (NR_044207) & 97.7 & - \\
\hline \multirow[t]{3}{*}{ Pseudonocardiaceae } & Pseudonocardia & 24 & S76 (JX007993) & P. carboxydivorans (NR_044092) & 99.2 & - \\
\hline & Saccharopolyspora* & 25 & S36\# (JX007965) & S. gloriosae (EU005371) & 99.2 & + \\
\hline & & 25 & S79 (JX007996) & S. gloriosae (EU005371) & 99.4 & + \\
\hline \multirow[t]{16}{*}{ Streptomycetaceae } & Streptomyces & 26 & S10\# (JX007952) & S. parvulus (NR_041119) & 99.8 & + \\
\hline & & 27 & S31\# (JX007961) & S. carnosus (AB184263) & 100 & + \\
\hline & & 28 & S39\# (JX007967) & S. djakartensis (NR_041178) & 99.5 & + \\
\hline & & 29 & S40\# (JX007968) & S. luteosporeus (AB184607) & 97.6 & + \\
\hline & & 30 & S41\# (JX007969) & S. rochei (NR_041091) & 100 & + \\
\hline & & 31 & S52 (JX007976) & S. flavofuscus (DQ026648) & 98.2 & - \\
\hline & & 32 & S59 (JX007982) & S. resistomycificus (NR_042100) & 99.8 & - \\
\hline & & 33 & S71 \# (JX007988) & S. anulatus (NR_041062) & 99.8 & + \\
\hline & & 34 & S72\# (JX007989) & S. xiamenensis (NR_044035) & 99.4 & + \\
\hline & & 35 & S73 (JX007990) & S. sclerotialus (NR_025620) & 98.3 & - \\
\hline & & 35 & S74 (JX007991) & S. sclerotialus (NR_025620) & 98.2 & - \\
\hline & & 36 & S75 (JX007992) & S. albidoflavus (NR_041095) & 99.3 & - \\
\hline & & 37 & S81\# (JX007998) & S. diastaticus (NR_043486) & 99.6 & + \\
\hline & & 38 & S82 (JX007999) & S. marinus (AB473554) & 97.8 & - \\
\hline & & 39 & S86\# (KJ094388) & S. griseorubens (NR_041066) & 100 & + \\
\hline & & 39 & S95 (KJ094394) & S. griseorubens (NR_041066) & 100 & + \\
\hline Streptosporangiaceae & Nonomuraea* & 40 & S88 (KJ094390) & N. ferruginea (NR_025996) & 98.7 & - \\
\hline
\end{tabular}

The 12 genera marked with *were cultivated from South China Sea sponges for the first time and the 17 strains marked with \# were selected for KS $\alpha$ gene analysis.

strains (S31, S40, S81, and S86) with spore pigment group. In addition, 10 sequences displayed $<93.6 \%$ similarity with their top matches, whose products could not be correlated with specific subtypes. Subsequent phylogenetic analysis also supported our clustering patterns based on maximum similarity.

\section{Small-scale Fermentation and Aromatic Polyketide Discovery}

Based on $\mathrm{KS}_{\alpha}$ sequence analysis, 10 strains were selected for small-scale fermentation (Table 3), among which one strain (Micromonospora aurantiaca S97) was used to test the production of putative benzoisochromanequinone, three strains (Streptomyces rochei S41, Streptomyces anulatus S71 and Nocardia araoensis S107) for putative angucyclines and other six strains (Streptomyces parvulus S10, Saccharopolyspora gloriosa S36, Streptomyces djakartensis S39, Streptomyces xiamenensis S72, Nocardiopsis alba S78, and Nocardiopsis halotolerans S92) for putative other subtypes. Expected products were preliminarily distinguished from the metabolite profiles according to their $\mathrm{UV} /$ vis absorption characteristics. Finally, one major metabolite present in the extract of Streptomyces anulatus strain S71 (Figure 3A) showed its UV-vis absorption (Figure 4) similar to that of typical angucyclines such as landomycin, which was absent in the control (Figure 3B). Subsequently, by using LC-MS, both HR ESI-MS $\left([\mathrm{M}+\mathrm{H}]^{+} \mathrm{m} / z=467.1326\right)$ (Figure 5) and UV data ( $\lambda_{\max }: 252,434 \mathrm{~nm}$ ) (Figure 4) of the target substance almost corresponded to the data reported for one angucycline amycomycin B (HRESIMS: $m / z 489.1154$ $[\mathrm{M}+\mathrm{Na}]^{+}$; UV $\lambda_{\max }: 249,427 \mathrm{~nm}$ ) (Figure 6) (Guo et al., 2012), indicating that the detected compound was either amycomycin $\mathrm{B}$ itself or its analog. This finding indicated that $S$. anulatus S71 produced angucycline compound under the lab culture condition. Unfortunately, we did not detect any expected aromatic polyketide from other strains under lab fermentation condition. 


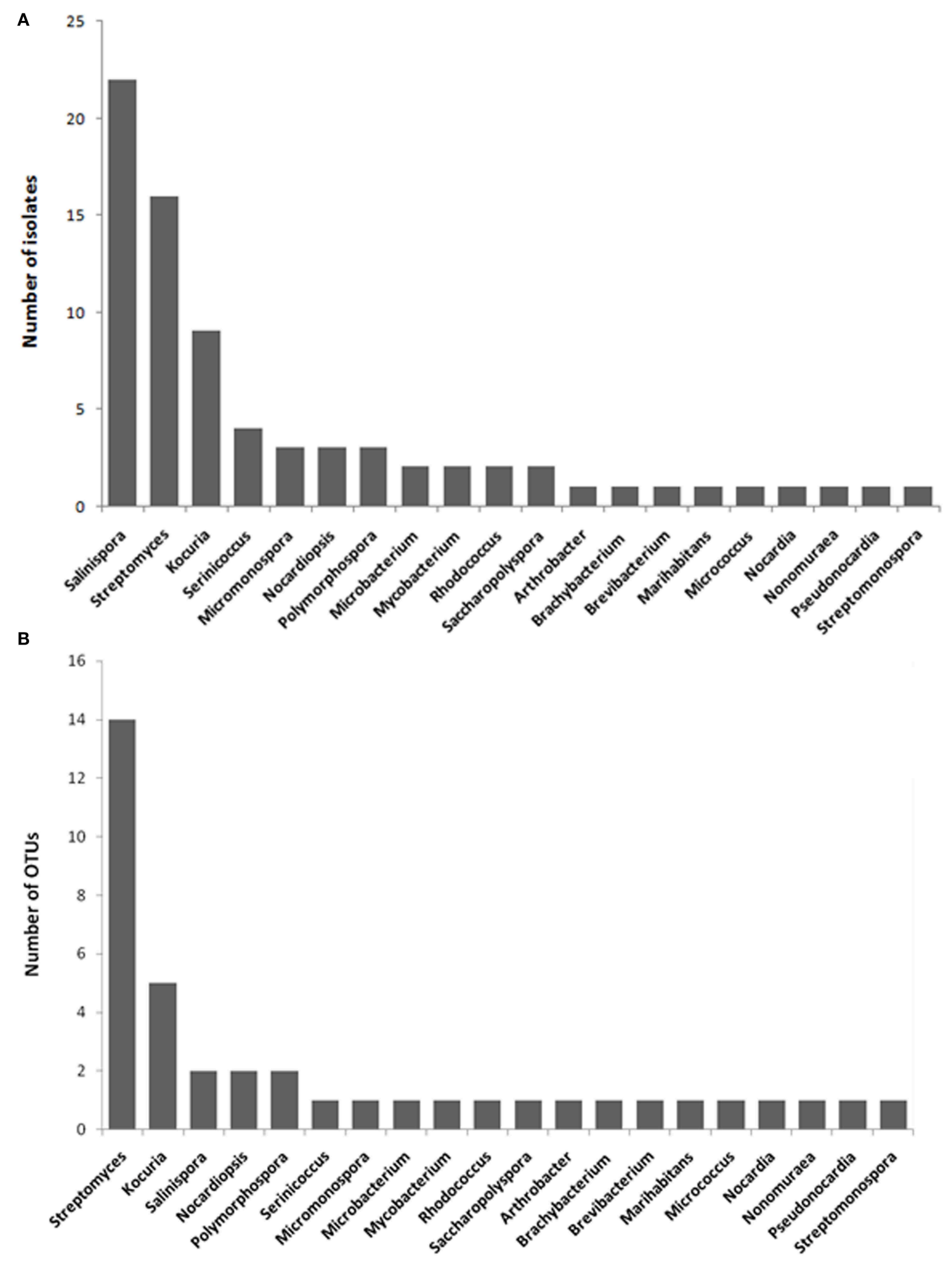

FIGURE 1 | Number of isolates (A) and OTUs per actinobacterial genus (B). 
TABLE 3 | $\mathrm{KS}_{\alpha}$ amino acid sequences.

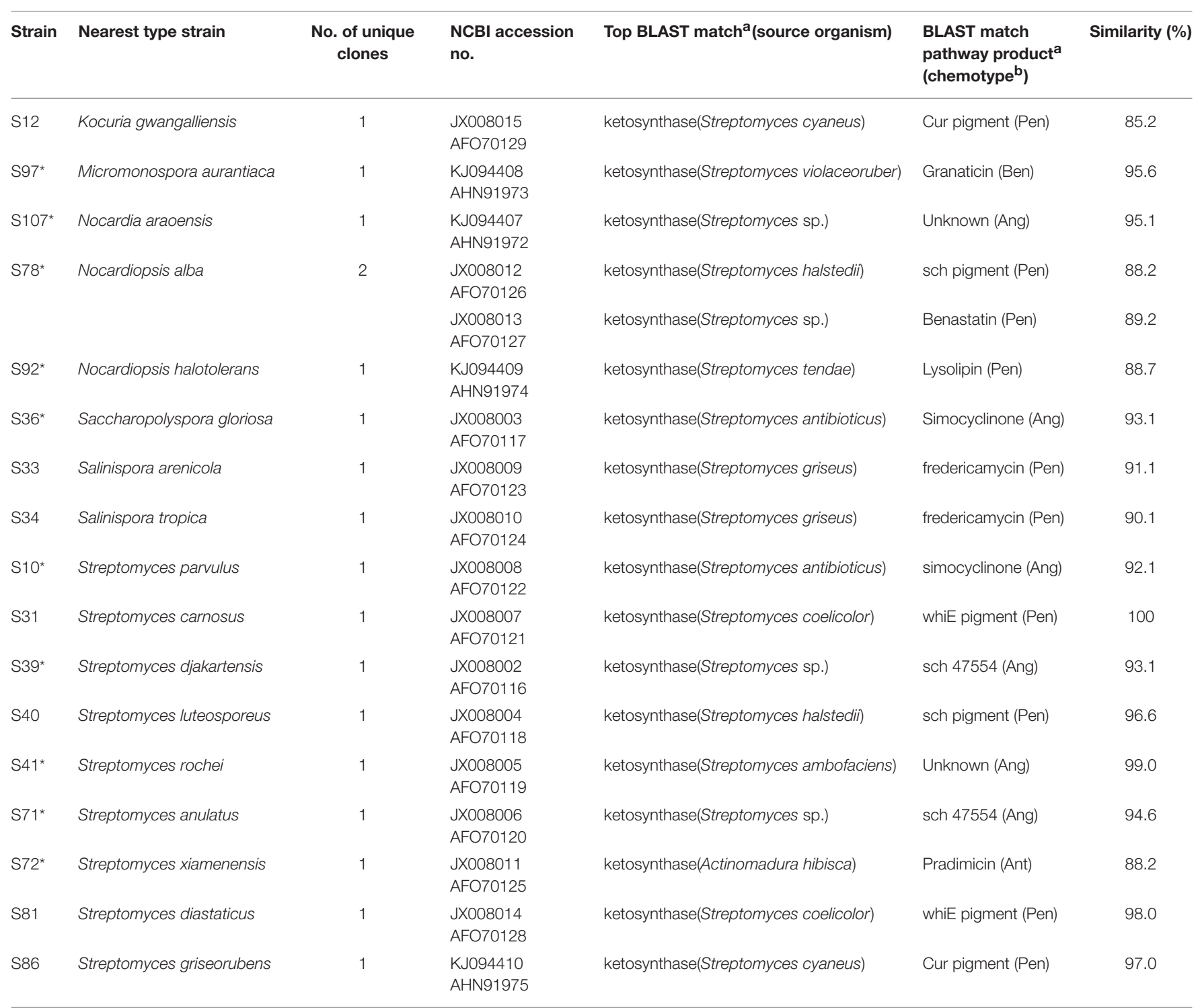

a Top BLAST matches are to the KS $\alpha$ domains associated with experimentally characterized biosynthetic pathways of aromatic polyketides.

${ }^{b}$ Pen-Pentangular polyphenols, Ben-Benzoisochromanequinones, Ang-Angucyclines, Ant-Anthracyclines.

The 10 strains marked with *were selected for small-scale fermentation.

\section{Discussion}

In this study, comprehensive investigation of 15 sponge species and combination of five culture media led to the isolation of 20 actinobacterial genera. The isolation of indigenous marine genera (Marihabitans, Salinispora, and Serinicoccus) showed the marine characteristic of the actinomycetes from the South China Sea sponges. Actinobacteria are widely dispersed throughout the marine environments, including water column, marine organisms, marine snow, and sediments (Ward and Bora, 2006). Here, we respectively compare the culturable diversity of the South China Sea sponge-associated actinomycetes with that of marine sediment-derived, coral-associated, and seawater-derived actinomycetes (Table 4). It is apparent that the actinobacterial diversity in any individual habitat cannot cover the diversity revealed in present study. Specifically, among the 20 genera from the South China Sea sponges, one genus (Marihabitans) has not been found from marine sediments, four genera (Marihabitans, Nonomuraea, Polymorphospora, and Streptomonospora) not isolated from corals, and six genera (Nonomuraea, Polymorphospora, Pseudonocardia, Saccharopolyspora, Salinispora, and Streptomonospora) not cultured from seawater. Consequently, South China Sea sponges displayed their advantage as a prolific source of culturable actinomycetes compared with other marine habitats.

Prior to our study, 15 actinomycete genera have been cultivated from South China Sea sponges, including 


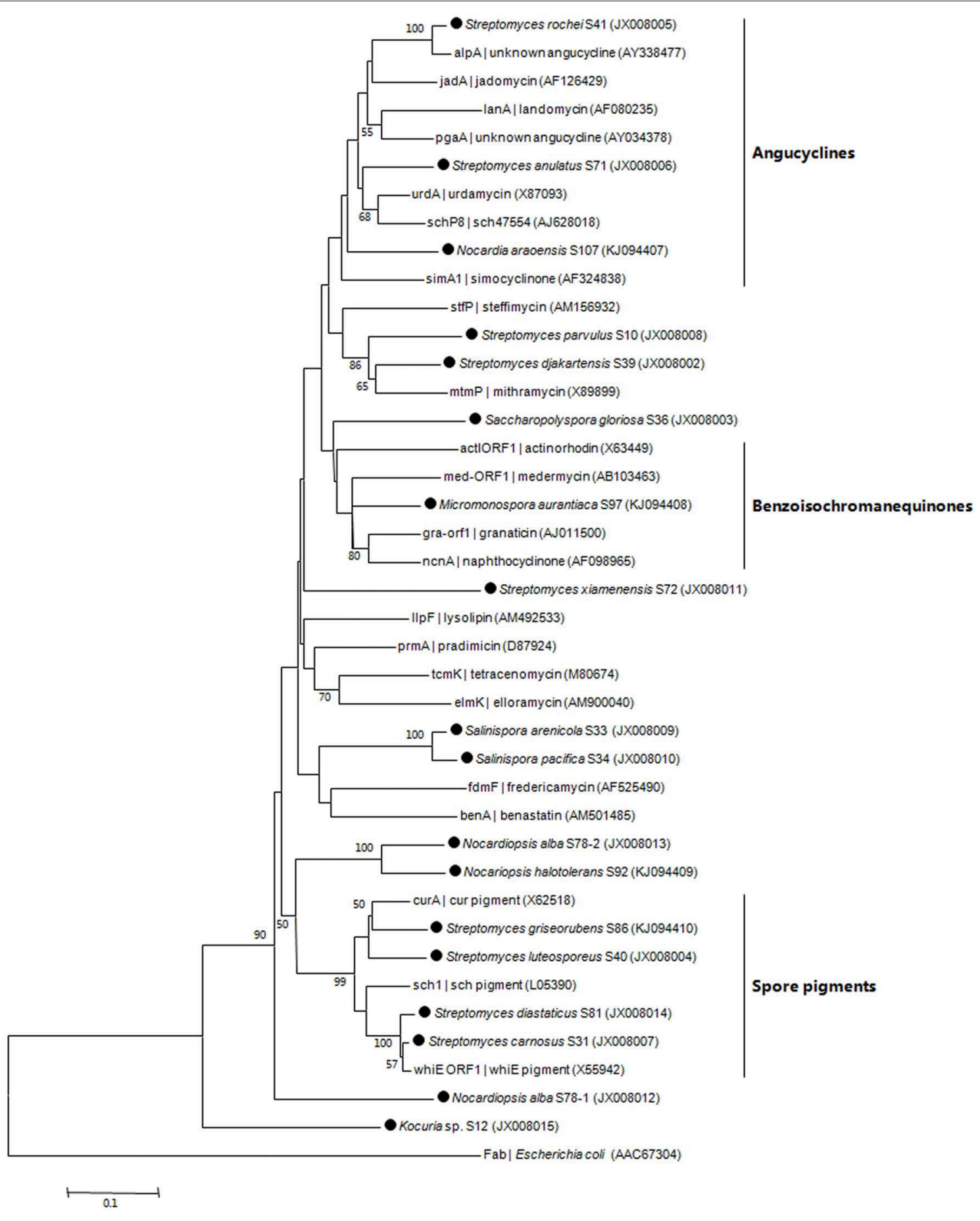

FIGURE 2 | Neighbor-joining tree constructed using aligned $\mathbf{K S}_{\alpha}$ domain amino acid sequences (203 amino acid positions). The sequences obtained in this work are marked by black dot. Next to the $\mathrm{KS}_{\alpha}$ gene name, the identified, or predicted compounds and GenBank accession number of the gene cluster are indicated. Boot strap values calculated from 1000 resamplings using neighborjoining are shown at the respective nodes when the calculated values were $50 \%$ or greater. The scale bar represents 0.1 substitutions per amino acid position.

Actinomadura, Catenuloplanes, Cellulosimicrobium, Gordonia, Micromonospora, Mycobacterium, Nocardia, Nocardiopsis, Pseudonocardia, Rhodococcus, Saccharomonospora, Salinispora, Sphaerisporangium, Streptomyces, and Verrucosispora. By investigating as many as 15 previously unexplored South China Sea sponges, the known diversity of sponge-associated actinomycetes was significantly extended, with a total of 27 genera successfully cultivated (including previously 

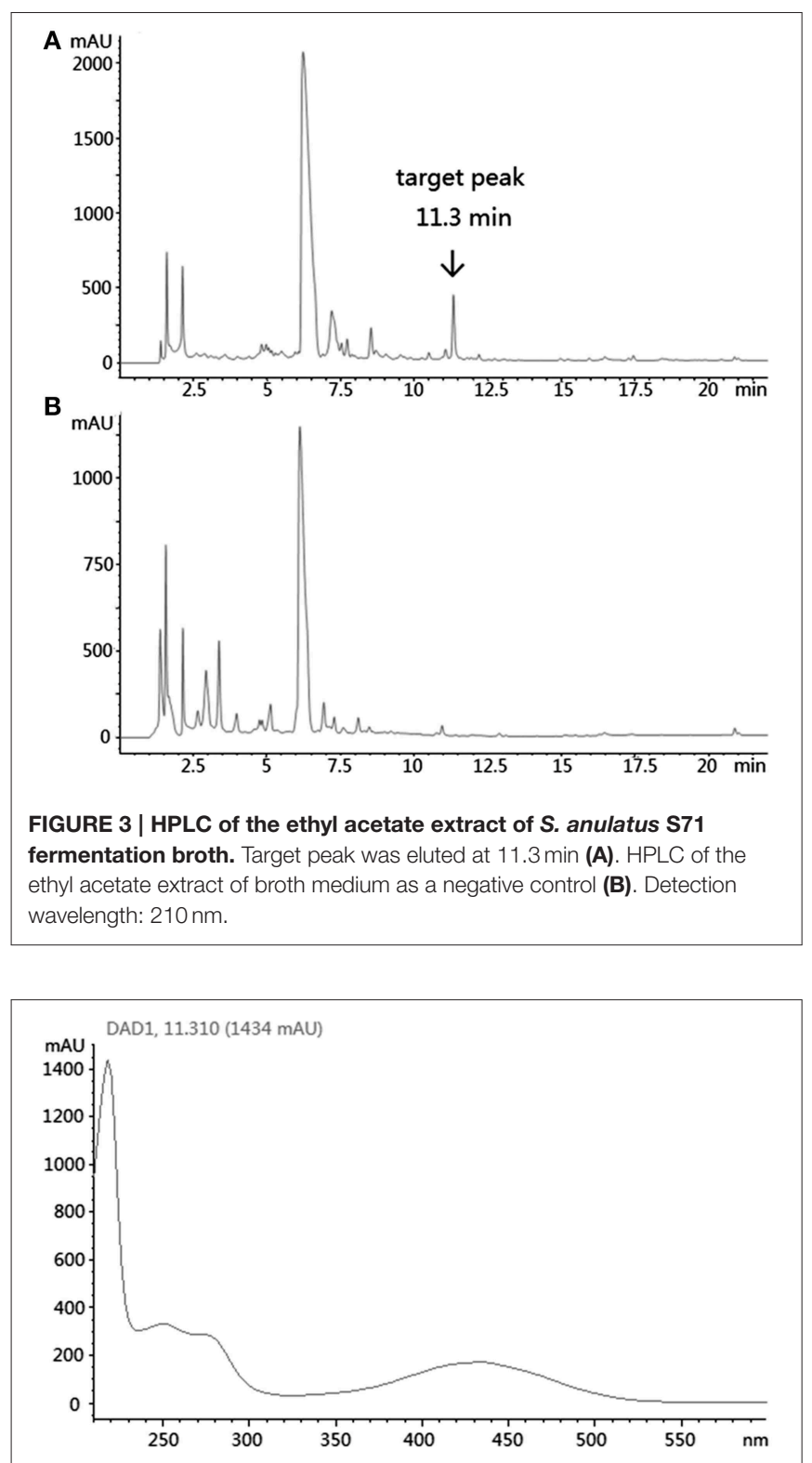

FIGURE 4 | UV/vis spectra of selected peak at $t_{R} 11.3 \mathrm{~min}$.

reported 15 genera and newly cultivated 12 genera in this study). Excitingly, three rare genera (Streptomonospora, Polymorphospora, and Marihabitans) were isolated from marine sponges for the first time. Streptomonospora is a group of strictly halophilic filamentous actinomycetes in Nocardiopsaceae. Streptomonospora strains were previously derived from hypersaline soil (Cai et al., 2008) and salt lake (Cai et al., 2009). Until recently, two Streptomonospora strains were found from marine sediments, indicating its existence in the marine environment (Zhang et al., 2013a). Polymorphospora is a genus in Micromonosporaceae, and Polymorphospora strains were mainly isolated from soil surrounding mangrove roots (Tamura et al., 2006). Marihabitans is a genus in Intrasporangiaceae (Kageyama et al., 2008). Notably, the genus is quite rare and only one strain was previously cultured from surface seawater (Kageyama et al., 2008).

Over the past decade, actinomycetes have been intensively isolated from sponges inhabiting the Yellow Sea, the Caribbean Sea, the Red Sea, and the Mediterranean Sea as well (Abdelmohsen et al., 2014a). By comparing the diversity of the sponge-associated actinomycetes from the separate geographical locations, we found that different region generally harbored distinct sponge-associated actinomycetes, including both common actinomycete genera (Micromonospora, Nocardiopsis, Rhodococcus, and Streptomyces) and respective different actinomycete groups (Table 5). Notably, seven genera (Catenuloplanes, Marihabitans, Polymorphospora, Saccharopolyspora, Serinicoccus, Sphaerisporangium, and Streptomonospora) not found from the sponges in other oceans were cultivated from the South China Sea sponges, indicating the biogeographic variability in the South China Sea sponge-associated actinobacterial communities.

The use of molecular approaches for describing microbial diversity has greatly enhanced the knowledge of population structure in sponge-associated bacterial communities. Diverse actinobacterial groups belonging to Actinobacteridae have been detected from various sponges (Simister et al., 2012). To our knowledge, at least 22 sponge-associated actinomycete genera have been revealed by molecular techniques, including Actinomyces, Agromyces, Amycolatopsis, Arthrobacter, Brevibacterium, Cellulosimicrobium, Corynebacterium, Kocuria, Microbacterium, Micrococcus, Microlunatus, Micromonospora, Mycobacterium, Nocardioides, Nocardiopsis, Propionibacterium, Pseudonocardia, Rhodococcus, Ruania, Saccharopolyspora, Streptomyces, and Verrucosispora. This number is much lower than that of the cultivated genera (60 genera) (Abdelmohsen et al., 2014a). Two factors are thought to lead to this result. First, the majority of the amplicon libraries were constructed using bacterial universal primers, thus it is difficult to detect those low-abundance actinobacterial groups. Second, environmental surveys based on $16 \mathrm{~S}$ rRNA gene sequencing preferred to describe the bacterial community structure at the phylum level but not genus level. Therefore, the diversity of spongeassociated actinomycetes was mainly revealed by culture-based methods. Notably, to date several genera (Actinomyces, Amycolatopsis, Microlunatus, Propionibacterium, Ruania) detected by molecular techniques have not been isolated from sponges, suggesting that the diversity is still worth exploring in future.

Sponges contain diverse actinobacterial groups, however, the ecological functions of the actinobacteria are hardly known. Sponge-associated actinomycetes produce bioactive small molecules like their terrestrial counterparts do. The possibility cannot be excluded that some compounds play an important role in the chemical ecology of sponge hosts. Considering actinomycete-derived secondary metabolites commonly occur in a very low concentration, the compounds are difficult to be extracted directly from sponges. Consequently, exploring the metabolic potential of the sponge-associated actinomycete strains facilitates the discovery of novel bioactive molecules. 


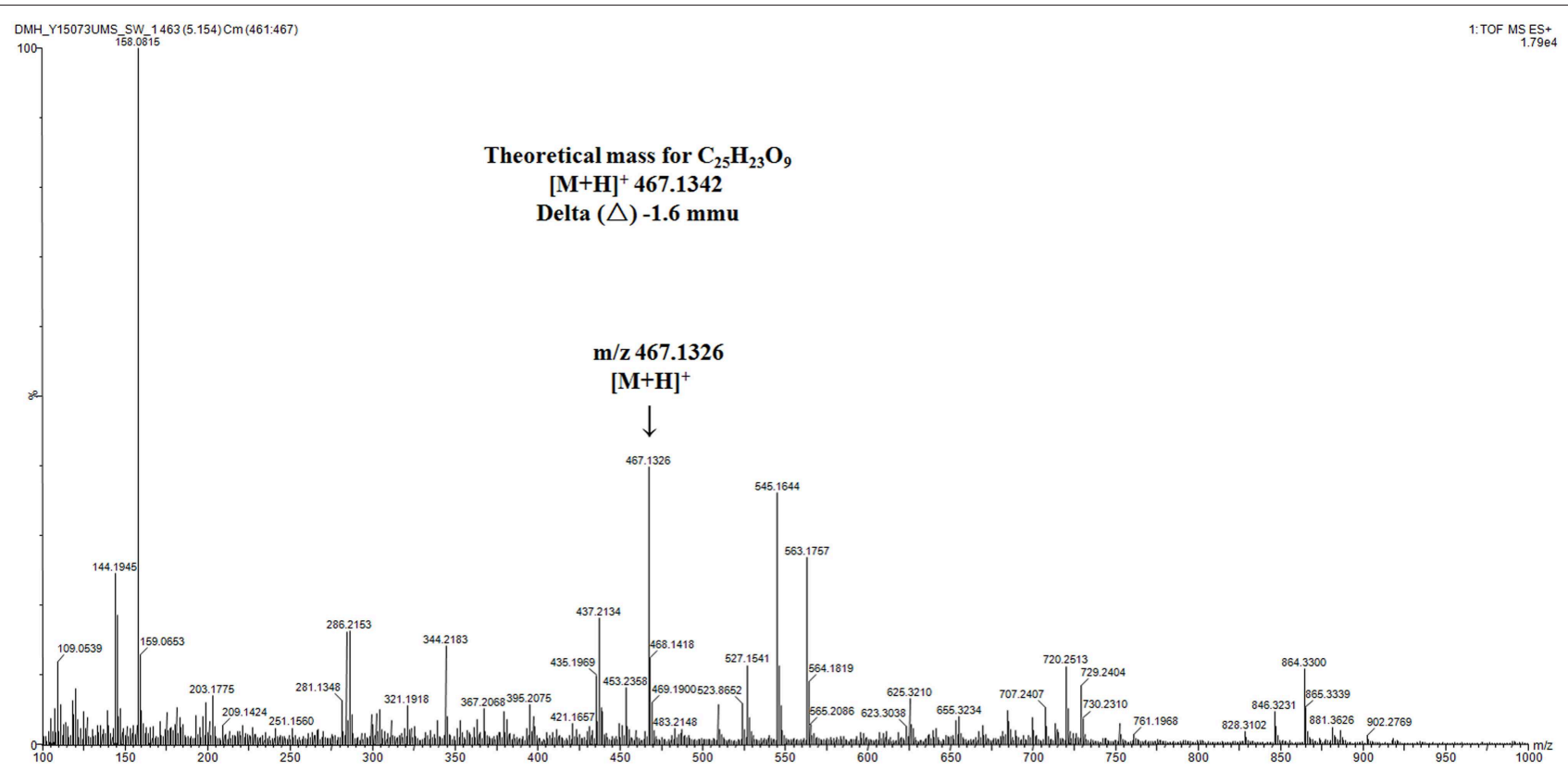

FIGURE 5 | High-resolution mass spectrum of selected ion at $\mathbf{t}_{\mathbf{R}} \mathbf{5 . 1 5} \mathbf{m i n}$ in TIC. mmu, milli-mass units.

Aromatic polyketides are known to be produced by a few taxa among diverse actinomycetes. Thus, knowing their taxonomic distribution facilitates the prioritization of strains for aromatic polyketide search and discovery. In this work, seven genera (Kocuria, Micromonospora, Nocardia, Nocardiopsis, Saccharopolyspora, Salinispora, and Streptomyces) were screened out as potential producers of aromatic polyketides, including both recognized and previously not recognized producers. Notably, strains related to Streptomyces, Micromonospora, Nocardia, Nocardiopsis, Saccharopolyspora, and Salinispora were known producers of aromatic polyketides (Sun et al., 2007; Perez et al., 2009; Ding et al., 2012; Sousa et al., 2012; Xie et al., 2012; Jensen et al., 2015). However, one genus (Kocuria) not traditionally associated with aromatic polyketide production was detected as well, suggesting that poorly studied genera may be potential producers of aromatic polyketides. To date, aromatic polyketides have not been isolated from strains related to Kocuria, therefore, their potential in aromatic polyketide biosynthesis deserves further exploration.

In recent years, phylogenetic prediction has been successfully applied in the discovery of type I polyketides (Gontang et al., 2010). By bioinformatic analyses of KS sequence the prediction was preliminarily made, and test for the production of target compounds was subsequently preformed to confirm the sequence-based analyses. Considering diverse tailoring enzymes involved in the aromatic polyketide biosynthesis (Schneider, 2005), we think it is not feasible to accurately predict target substance merely based on $\mathrm{KS}_{\alpha}$ sequence analysis. However, due to the conserved property of $\mathrm{KS}_{\alpha}$ domain, it is possible to correlate one $\mathrm{KS}_{\alpha}$ sequence (one strain) with one specific subtype (Metsä-Ketelä et al., 2002). Among 17 representative

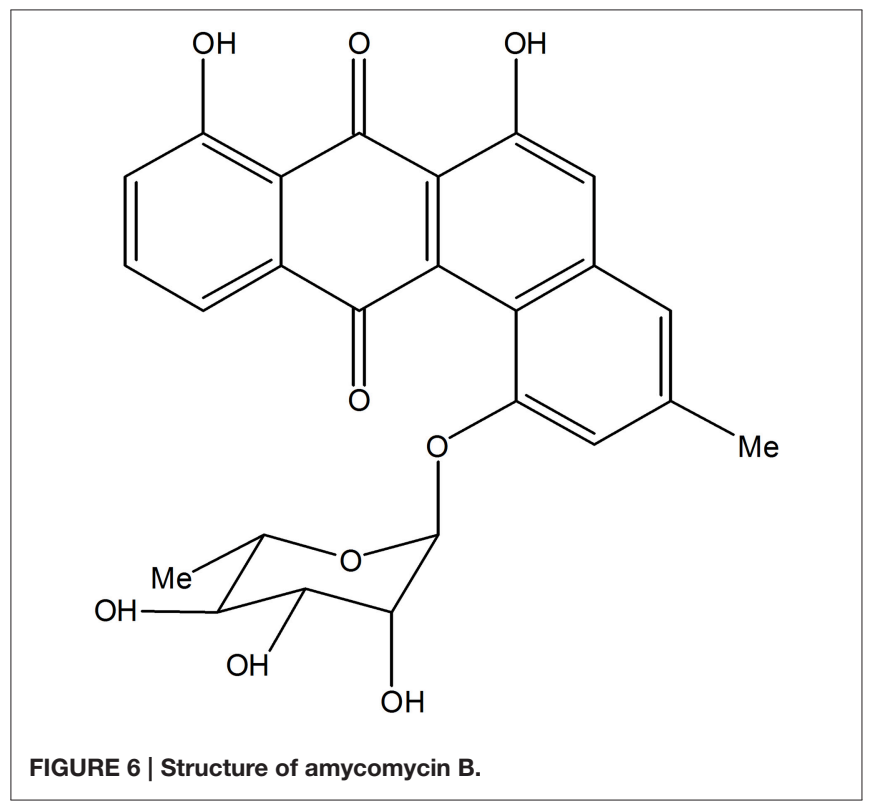

strains, eight were specifically related to three subgroups, respectively angucyclines, benzoisochromanequinones, and spore pigments (Figure 2). The angucycline group is the largest group of aromatic polyketides, rich in chemical scaffolds and biological activities (Kharel et al., 2012). The benzoisochromanequinone group comprises fewer compounds than angucyclines but its members show a wide range of biological activities as well (Brimble et al., 1999). Additionally, other nine strains cannot be correlated with specific chemotypes (Figure 2). However, these strains should not be neglected 
TABLE 4 | Comparison of the culturable diversity of South China Sea sponge-associated actinomycetes with that of marine sediment-derived, coral-associated, and seawater-derived actinomycetes.

\begin{tabular}{|c|c|c|c|c|}
\hline $\begin{array}{l}\text { South China Sea } \\
\text { sponge-associated } \\
\text { actinomycetes }\end{array}$ & $\begin{array}{l}\text { Marine sediment-derived } \\
\text { actinomycetes }\end{array}$ & $\begin{array}{l}\text { Coral-associated } \\
\text { actinomycetes }\end{array}$ & $\begin{array}{l}\text { Seawater-derived } \\
\text { actinomycetes }\end{array}$ & References \\
\hline Arthrobacter & + & + & + & Wietz et al., 2012; Yang et al., 2013; Zhang et al., 2014 \\
\hline Brachybacterium & + & + & + & Wang et al., 2010; Yang et al., 2013; Zhang et al., 2014 \\
\hline Brevibacterium & + & + & + & Wang et al., 2010; Yang et al., 2013; Zhang et al., 2014 \\
\hline Kocuria & + & + & + & Wang et al., 2010; Yang et al., 2013; Zhang et al., 2014 \\
\hline Marihabitans & - & - & + & Kageyama et al., 2008 \\
\hline Microbacterium & + & + & + & Wang et al., 2010; Yang et al., 2013; Zhang et al., 2014 \\
\hline Micrococcus & + & + & + & Harwati et al., 2007; Yang et al., 2013; Zhang et al., 2014 \\
\hline Micromonospora & + & + & $+^{*}$ & Chen et al., 2011; Yang et al., 2013 \\
\hline Mycobacterium & + & + & + & Al-Awadhi et al., 2012; Yang et al., 2013; Zhang et al., 2014 \\
\hline Nocardia & + & + & $+^{*}$ & Chen et al., 2011; Zhang et al., 2013b \\
\hline Nocardiopsis & + & + & $+^{*}$ & Maldonado et al., 2005; Zhang et al., 2013b \\
\hline Nonomuraea & + & - & - & Maldonado et al., 2005 \\
\hline Polymorphospora & + & - & - & Tamura et al., 2006 \\
\hline Pseudonocardia & + & + & - & Maldonado et al., 2005; Zhang et al., 2013b \\
\hline Rhodococcus & + & + & + & Chen et al., 2011; Al-Awadhi et al., 2012; Yang et al., 2013 \\
\hline Saccharopolyspora & + & + & - & Maldonado et al., 2005; Zhang et al., 2013b \\
\hline Salinispora & + & $+^{*}$ & - & Gontang et al., 2007 \\
\hline Serinicoccus & + & $+^{*}$ & + & Yi et al., 2004; Gontang et al., 2007 \\
\hline Streptomonospora & + & - & - & Zhang et al., 2013a \\
\hline Streptomyces & + & + & + & Chen et al., 2011; Zhu et al., 2011; Yang et al., 2013 \\
\hline
\end{tabular}

+ , The actinomycete genera are also cultivated from other marine habitats.

-, The actinomycete genera have not been cultivated from other marine habitats.

*16S rRNA gene sequences were submitted to GenBank but paper is unpublished.

because they potentially have the capacity to produce novel subtypes.

For the rapid identification of aromatic polyketides from crude culture extracts, it is critical to develop an efficient approach. At present, it is feasible to determine the elemental composition of compounds in mixtures and identify natural products using LC/MS and UV/vis spectra (Nielsen et al., 2011; El-Elimat et al., 2013). In the case of aromatic polyketides, UV/vis spectra provided important clues on the presence of unsaturated cyclohexanedione structure and polyphenolic ring system and thus indicated the compound type, and LC/MS analysis gave precise molecular weight and suggested molecular formula of target signal. Subsequently, the molecular formulas were used as queries to match those reported aromatic polyketides in database. If some compounds were retrieved, then their UV-vis absorption maxima are compared with target substance. Only when both UV/vis spectra and high-resolution molecular weight were consistent, the compound was identified as known one or its analog. This method avoided large-scale fermentation and purification processes, thus saved time and resource. It can be used as a dereplication protocol for aromatic polyketides and enhance the efficiency of discovering novel aromatic polyketides.

To our knowledge, actinomycete strains generally contain a number of biosynthetic gene clusters. However, only a few corresponding metabolites have been obtained until now. Apparently, the majority of the biosynthetic gene clusters are unexpressed under standardized laboratory conditions, which leads to a low efficiency in the discovery of their secondary metabolites. Similarly, it is also present in the aromatic polyketide discovery from the South China Sea sponge-associated actinomycetes. Surveying recent advances in microbial natural product discovery, we think two strategies can be considered to exclusively explore the metabolic potential of the strains. One is to try activating silent biosynthetic pathways through external cues, cocultivation and stress since it has achieved great success in the natural product discovery from fungi and actinomycetes (Scherlach and Hertweck, 2009). The other is to apply genetic manipulation techniques such as gene cluster cloning and heterologous expression because it has shown unique advantage in harvesting rare skeletons of aromatic polyketides (Feng et al., 2011). They should be preferentially attempted in future work.

In summary, a total of 20 actinomycete genera were isolated from the South China Sea sponges, including three rare genera (Marihabitans, Polymorphospora, and Streptomonospora) found from sponges first time. Potential aromatic polyketide producers were distributed in seven genera (Kocuria, Micromonospora, Nocardia, Nocardiopsis, Saccharopolyspora, Salinispora, and Streptomyces). By small-scale fermentation, one angucycline compound was detected from 
TABLE 5 | Comparison of the culturable diversity of the sponge-associated actinomycetes from the South China Sea, Yellow Sea, Caribbean Sea, Red Sea, and Mediterranean Sea.

\begin{tabular}{|c|c|c|c|c|c|}
\hline Actinomycete genera & $\begin{array}{l}\text { South China Sea } \\
\text { sponge-associated } \\
\text { actinomycetes }\end{array}$ & $\begin{array}{c}\text { Yellow Sea } \\
\text { sponge-associated } \\
\text { actinomycetes }\end{array}$ & $\begin{array}{c}\text { Caribbean } \\
\text { sponge-associated } \\
\text { actinomycetes }\end{array}$ & $\begin{array}{c}\text { Red Sea } \\
\text { sponge-associated } \\
\text { actinomycetes }\end{array}$ & $\begin{array}{c}\text { Mediterranean } \\
\text { sponge-associated } \\
\text { actinomycetes }\end{array}$ \\
\hline Actinoalloteichus & - & + & - & - & - \\
\hline Actinokineospora & - & - & - & + & - \\
\hline Actinomadura & + & + & - & - & - \\
\hline Arthrobacter & + & - & - & + & - \\
\hline Blastococcus & - & + & - & - & - \\
\hline Brachybacterium & + & - & - & + & - \\
\hline Brevibacterium & + & - & - & + & - \\
\hline Catenuloplanes* & + & - & - & - & - \\
\hline Cellulosimicrobium & + & - & + & - & - \\
\hline Corynebacterium & - & - & - & + & + \\
\hline Curtobacterium & - & - & - & + & - \\
\hline Dietzia & - & - & - & + & - \\
\hline Georgenia & - & + & - & - & - \\
\hline Gordonia & + & + & - & - & + \\
\hline Kocuria & + & - & - & + & + \\
\hline Marihabitans* & + & - & - & - & - \\
\hline Microbacterium & + & - & + & + & - \\
\hline Micrococcus & + & - & - & + & - \\
\hline Micromonospora & + & + & + & + & + \\
\hline Mycobacterium & + & - & - & + & + \\
\hline Nocardia & + & + & - & + & - \\
\hline Nocardiopsis & + & + & - & + & + \\
\hline Nonomuraea & + & + & - & - & - \\
\hline Polymorphospora* & + & - & - & - & - \\
\hline Pseudonocardia & + & + & - & - & - \\
\hline Rhodococcus & + & + & - & + & + \\
\hline Rothia & - & - & - & + & + \\
\hline Rubrobacter & - & - & - & - & + \\
\hline Saccharomonospora & + & - & - & + & - \\
\hline Saccharopolyspora* & + & - & - & - & - \\
\hline Salinispora & + & - & + & + & - \\
\hline Serinicoccus ${ }^{\star}$ & + & - & - & - & - \\
\hline Solwaraspora & - & - & + & - & - \\
\hline Sphaerisporangium* & + & - & - & - & - \\
\hline Streptomonospora* & + & - & - & - & - \\
\hline Streptomyces & + & + & + & - & + \\
\hline Verrucosispora & + & - & + & - & - \\
\hline
\end{tabular}

The genera marked with *were currently limited to South China Sea. The shading on rows highlight the sponge-associated actinomycete genera widely distributed in distinct oceans.

one Streptomyces isolate. This work advanced our knowledge of sponge-associated actinomycetes regarding their diversity and biogeography, and revealed their potential in aromatic polyketide production.

\section{Author Contributions}

ZL and WS designed the study. LH identified the sponge samples. WS performed the experiments. WS and FZ analyzed the data. WS, ZL, and KL wrote the manuscript. All authors read and approved the final manuscript.

\section{Acknowledgments}

This work was supported by the National Natural Science Foundation of China (Grant No. 81102417) and the High-Tech Research and Development Program of China (2013AA092901).

\section{Supplementary Material}

The Supplementary Material for this article can be found online at: http://journal.frontiersin.org/article/10.3389/fmicb. 2015.01048 


\section{References}

Abdelmohsen, U. R., Bayer, K., and Hentschel, U. (2014a). Diversity, abundance and natural products of marine sponge-associated actinomycetes. Nat. Prod. Rep. 31, 381-399. doi: 10.1039/c3np70111e

Abdelmohsen, U. R., Pimentel-Elardo, S. M., Hanora, A., Radwan, M., Abou-ElEla, S. H., Ahmed, S., et al. (2010). Isolation, phylogenetic analysis and antiinfective activity screening of marine sponge-associated actinomycetes. Mar. Drugs 8, 399-412. doi: 10.3390/md8030399

Abdelmohsen, U. R., Yang, C., Horn, H., Hajjar, D., Ravasi, T., and Hentschel, U. (2014b). Actinomycetes from Red Sea sponges: sources for chemical and phylogenetic diversity. Mar. Drugs 12, 2771-2789. doi: 10.3390/md12052771

Al-Awadhi, H., Al-Mailem, D., Dashti, N., Khanafer, M., and Radwan, S. (2012). Indigenous hydrocarbon-utilizing bacterioflora in oil-polluted habitats in Kuwait, two decades after the greatest man-made oil spill. Arch. Microbiol. 194, 689-705. doi: 10.1007/s00203-012-0800-7

Altschul, S. F., Gish, W., Miller, W., Myers, E. W., and Lipman, D. J. (1990). Basic local alignment search tool. J. Mol. Biol. 215, 403-410.

Brimble, M. A., Duncalf, L. J., and Nairn, M. R. (1999). Pyranonaphthoquinone antibiotics-isolation, structure and biological activity. Nat. Prod. Rep. 16, 267-281. doi: 10.1039/a804287j

Cai, M., Tang, S. K., Chen, Y. G., Li, Y., Zhang, Y. Q., and Li, W. J. (2009). Streptomonospora amylolytica sp nov and Streptomonospora flavalba sp nov., two novel halophilic actinomycetes isolated from a salt lake. Int. J. Syst. Evol. Microbiol. 59, 2471-2475. doi: 10.1099/ijs.0.007682-0

Cai, M., Zhi, X. Y., Tang, S. K., Zhang, Y. Q., Xu, L. H., and Li, W. J. (2008). Streptomonospora halophila sp nov., a halophilic actinomycete isolated from a hypersaline soil. Int. J. Syst. Evol. Microbiol. 58, 1556-1560. doi: 10.1099/ijs.0.65513-0

Chen, F. F., Lin, L., Wang, L., Tan, Y., Zhou, H. X., Wang, Y. G., et al. (2011). Distribution of dTDP-glucose-4,6-dehydratase gene and diversity of potential glycosylated natural products in marine sediment-derived bacteria. Appl. Microbiol. Biotechnol. 90, 1347-1359. doi: 10.1007/s00253-011-3112-y

Ding, Z. G., Zhao, J. Y., Li, M. G., Huang, R., Li, Q. M., Cui, X. L., et al. (2012). Griseusins F and G, spiro-naphthoquinones from a tin mine tailingsderived alkalophilic Nocardiopsis species. J. Nat. Prod. 75, 1994-1998. doi: $10.1021 / \mathrm{np} 3004936$

El-Elimat, T., Figueroa, M., Ehrmann, B. M., Cech, N. B., Pearce, C. J., and Oberlies, N. H. (2013). High-resolution MS, MS/MS, and UV database of fungal secondary metabolites as a dereplication protocol for bioactive natural products. J. Nat. Prod. 76, 1709-1716. doi: 10.1021/np4004307

Feng, Z., Kallifidas, D., and Brady, S. F. (2011). Functional analysis of environmental DNA-derived type II polyketide synthases reveals structurally diverse secondary metabolites. Proc. Natl. Acad. Sci. U.S.A. 108, 12629-12634. doi: $10.1073 /$ pnas. 1103921108

Gontang, E. A., Fenical, W., and Jensen, P. R. (2007). Phylogenetic diversity of gram-positive bacteria cultured from marine sediments. Appl. Environ. Microbiol. 73, 3272-3282. doi: 10.1128/AEM.02811-06

Gontang, E. A., Gaudêncio, S. P., Fenical, W., and Jensen, P. R. (2010). Sequencebased analysis of secondary-metabolite biosynthesis in marine Actinobacteria. Appl. Environ. Microbiol. 76, 2487-2499. doi: 10.1128/aem.02852-09

Guo, Z. K., Liu, S. B., Jiao, R. H., Wang, T., Tan, R. X., and Ge, H. M. (2012). Angucyclines from an insect-derived actinobacterium Amycolatopsis sp HCa1 and their cytotoxic activity. Bioorg. Med. Chem. Lett. 22, 7490-7493. doi: 10.1016/j.bmcl.2012.10.048

Harwati, T. U., Kasai, Y., Kodama, Y., Susilaningsih, D., and Watanabe, K. (2007). Characterization of diverse hydrocarbon-degrading bacteria isolated from Indonesian seawater. Microbes Environ. 22, 412-415. doi: 10.1264/jsme2.22.412

Hertweck, C., Luzhetskyy, A., Rebets, Y., and Bechthold, A. (2007). Type II polyketide synthases: gaining a deeper insight into enzymatic teamwork. Nat. Prod. Rep. 24, 162-190. doi: 10.1039/b507395m

Hornung, A., Bertazzo, M., Dziarnowski, A., Schneider, K., Welzel, K., Wohlert, S. E., et al. (2007). A genomic screening approach to the structure-guided identification of drug candidates from natural sources. Chembiochem 8, 757-766. doi: 10.1002/cbic. 200600375

Jensen, P. R., Moore, B. S., and Fenical, W. (2015). The marine actinomycete genus Salinispora: a model organism for secondary metabolite discovery. Nat. Prod. Rep. 32, 738-751. doi: 10.1039/c4np00167b
Jiang, S. M., Li, X., Zhang, L., Sun, W., Dai, S. K., Xie, L. W., et al. (2008). Culturable actinobacteria isolated from marine sponge Iotrochota sp. Mar. Biol. 153, 945-952. doi: 10.1007/s00227-007-0866-y

Jiang, S., Sun, W., Chen, M., Dai, S., Zhang, L., Liu, Y., et al. (2007). Diversity of culturable actinobacteria isolated from marine sponge Haliclona sp. Antonie Van Leeuwenhoek 92, 405-416. doi: 10.1007/s10482-007-9169-Z

Kageyama, A., Haga, T., Kasai, H., Shizuri, Y., Omura, S., and Takahashi, Y. (2008). Marihabitans asiaticum gen. nov., sp nov., a meso-diaminopimelic acidcontaining member of the family Intrasporangiaceae. Int. J. Syst. Evol. Microbiol. 58, 2429-2432. doi: 10.1099/ijs.0.65210-0

Karuppiah, V., Li, Y., Sun, W., Feng, G., and Li, Z. (2015). Functional genebased discovery of phenazines from the actinobacteria associated with marine sponges in the South China Sea. Appl. Microbiol. Biotechnol. 99, 5939-5950. doi: 10.1007/s00253-015-6547-8

Kharel, M. K., Pahari, P., Shepherd, M. D., Tibrewal, N., Nybo, S. E., Shaaban, K. A., et al. (2012). Angucyclines: biosynthesis, mode-of-action, new natural products, and synthesis. Nat. Prod. Rep. 29, 264-325. doi: 10.1039/c1np00068c

Kim, J., and Yi, G. S. (2012). PKMiner: a database for exploring type II polyketide synthases. BMC Microbiol. 12:169. doi: 10.1186/1471-2180-12-169

Li, C. Q., Liu, W. C., Zhu, P., Yang, J. L., and Cheng, K. D. (2011). Phylogenetic diversity of bacteria associated with the marine sponge Gelliodes carnosa collected from the Hainan Island coastal waters of the South China Sea. Microb. Ecol. 62, 800-812. doi: 10.1007/s00248-011-9896-6

Love, G. D., Grosjean, E., Stalvies, C., Fike, D. A., Grotzinger, J. P., Bradley, A. S., et al. (2009). Fossil steroids record the appearance of Demospongiae during the Cryogenian period. Nature 457, 718-721. doi: 10.1038/nature07673

Maldonado, L. A., Stach, J. E. M., Pathom-aree, W., Ward, A. C., Bull, A. T., and Goodfellow, M. (2005). Diversity of cultivable actinobacteria in geographically widespread marine sediments. Antonie Van Leeuwenhoek 87, 11-18. doi: 10.1007/s10482-004-6525-0

Metsä-Ketelä, M., Halo, L., Munukka, E., Hakala, J., Mäntsälä, P., and Ylihonko, K. (2002). Molecular evolution of aromatic polyketides and comparative sequence analysis of polyketide ketosynthase and 16S ribosomal DNA genes from various Streptomyces species. Appl. Environ. Microbiol. 68, 4472-4479. doi: 10.1128/aem.68.9.4472-4479.2002

Metsä-Ketelä, M., Salo, V., Halo, L., Hautala, A., Hakala, J., Mäntsälä, P., et al. (1999). An efficient approach for screening minimal PKS genes from Streptomyces. FEMS Microbiol. Lett. 180, 1-6.

Mincer, T. J., Jensen, P. R., Kauffman, C. A., and Fenical, W. (2002). Widespread and persistent populations of a major new marine actinomycete taxon in ocean sediments. Appl. Environ. Microbiol. 68, 5005-5011. doi: 10.1128/aem.68.10.5005-5011.2002

Motohashi, K., Takagi, M., and Shin-Ya, K. (2010). Tetracenoquinocin and 5iminoaranciamycin from a sponge-derived Streptomyces sp. Sp080513GE-26. J. Nat. Prod. 73, 755-758. doi: 10.1021/np9007409

Nielsen, K. F., Mansson, M., Rank, C., Frisvad, J. C., and Larsen, T. O. (2011). Dereplication of microbial natural products by LC-DAD-TOFMS. J. Nat. Prod. 74, 2338-2348. doi: 10.1021/np200254t

Peréz, M., Schleissner, C., Rodríguez, P., Zuniga, P., Benedit, G., Sanchez-Sancho, F., et al. (2009). PM070747, a new cytotoxic angucyclinone from the marinederived Saccharopolyspora taberi PEM-06-F23-019B. J. Antibiot. 62, 167-169. doi: $10.1038 /$ ja.2008.27

Puglisi, M. P., Sneed, J. M., Sharp, K. H., Ritson-Williams, R., and Paul, V. J. (2014). Marine chemical ecology in benthic environments. Nat. Prod. Rep. 31, 1510-1553. doi: 10.1039/c4np00017j

Scherlach, K., and Hertweck, C. (2009). Triggering cryptic natural product biosynthesis in microorganisms. Org. Biomol. Chem. 7, 1753-1760. doi: $10.1039 / \mathrm{b} 821578 \mathrm{~b}$

Schneemann, I., Kajahn, I., Ohlendorf, B., Zinecker, H., Erhard, A., Nagel, K., et al. (2010a). Mayamycin, a cytotoxic polyketide from a Streptomyces strain isolated from the marine sponge Halichondria panicea. J. Nat. Prod. 73, 1309-1312. doi: $10.1021 / \mathrm{np} 100135 \mathrm{~b}$

Schneemann, I., Nagel, K., Kajahn, I., Labes, A., Wiese, J., and Imhoff, J. F. (2010b). Comprehensive investigation of marine Actinobacteria associated with the sponge Halichondria panicea. Appl. Environ. Microbiol. 76, 3702-3714. doi: 10.1128/aem.00780-10

Schneider, G. (2005). Enzymes in the biosynthesis of aromatic polyketide antibiotics. Curr. Opin. Struct. Biol. 15, 629-636. doi: 10.1016/j.sbi.2005.10.002 
Simister, R. L., Deines, P., Botté, E. S., Webster, N. S., and Taylor, M. W. (2012). Sponge-specific clusters revisited: a comprehensive phylogeny of sponge-associated microorganisms. Environ. Microbiol. 14, 517-524. doi: 10.1111/j.1462-2920.2011.02664.x

Sousa, T. D., Jimenez, P. C., Ferreira, E. G., Silveira, E. R., Braz, R., Pessoa, O. D. L., et al. (2012). Anthracyclinones from Micromonospora sp. J. Nat. Prod. 75, 489-493. doi: 10.1021/np200795p

Stach, J. E. M., Maldonado, L. A., Ward, A. C., Goodfellow, M., and Bull, A. T. (2003). New primers for the class Actinobacteria: application to marine and terrestrial environments. Environ. Microbiol. 5, 828-841. doi: 10.1046/j.14622920.2003.00483.X

Sun, C. H., Wang, Y., Wang, Z., Zhou, J. Q., Jin, W. Z., You, X. F., et al. (2007). Chemomicin A, a new angucyclinone antibiotic produced by Nocardia mediterranei subsp kanglensis 1747-64. J. Antibiot. 60, 211-215. doi: 10.1038/ja.2007.25

Sun, W., Dai, S., Jiang, S., Wang, G., Liu, G., Wu, H., et al. (2010). Culturedependent and culture-independent diversity of Actinobacteria associated with the marine sponge Hymeniacidon perleve from the South China Sea. Antonie Van Leeuwenhoek 98, 65-75. doi: 10.1007/s10482-010-9430-8

Tamura, K., Dudley, J., Nei, M., and Kumar, S. (2007). MEGA4: molecular evolutionary genetics analysis (MEGA) software version 4.0. Mol. Biol. Evol. 24, 1596-1599. doi: 10.1093/molbev/msm092

Tamura, T., Hatano, K., and Suzuki, K. (2006). A new genus of the family Micromonosporaceae, Polymorphospora gen. nov., with description of Polymorphospora rubra sp. nov. Int. J. Syst. Evol. Microbiol. 56, 1959-1964. doi: 10.1099/ijs.0.64046-0

Taylor, M. W., Radax, R., Steger, D., and Wagner, M. (2007). Sponge-associated microorganisms: evolution, ecology, and biotechnological potential. Microbiol. Mol. Biol. Rev. 71, 295-347. doi: 10.1128/mmbr.00040-06

Valliappan, K., Sun, W., and Li, Z. Y. (2014). Marine actinobacteria associated with marine organisms and their potentials in producing pharmaceutical natural products. Appl. Microbiol. Biotechnol. 98, 7365-7377. doi: 10.1007/s00253-0145954-6

Vicente, J., Stewart, A., Song, B., Hill, R. T., and Wright, J. L. (2013). Biodiversity of actinomycetes associated with Caribbean sponges and their potential for natural product discovery. Mar. Biotechnol. 15, 413-424. doi: 10.1007/s10126013-9493-4

Wang, L., Wang, W., Lai, Q., and Shao, Z. (2010). Gene diversity of CYP153A and AlkB alkane hydroxylases in oil-degrading bacteria isolated from the Atlantic Ocean. Environ. Microbiol. 12, 1230-1242. doi: 10.1111/j.14622920.2010.02165.x

Ward, A. C., and Bora, N. (2006). Diversity and biogeography of marine actinobacteria. Curr. Opin. Microbiol. 9, 279-286. doi: 10.1016/j.mib.2006.04.004

Wietz, M., Mansson, M., Bowman, J. S., Blom, N., Ng, Y., and Gram, L. (2012). Wide distribution of closely related, antibiotic-producing Arthrobacter strains throughout the Arctic Ocean. Appl. Environ. Microbiol. 78, 2039-2042. doi: 10.1128/AEM.07096-11

Woese, C. R., Gutell, R., Gupta, R., and Noller, H. F. (1983). Detailed analysis of the higher-order structure of 16S-like ribosomal ribonucleic acids. Microbiol. Rev. $47,621-669$.
Xi, L., Ruan, J., and Huang, Y. (2012). Diversity and biosynthetic potential of culturable actinomycetes associated with marine sponges in the China seas. Int. J. Mol. Sci. 13, 5917-5932. doi: 10.3390/ijms 13055917

Xie, Z. P., Liu, B., Wang, H. P., Yang, S. X., Zhang, H. Y., Wang, Y. P., et al. (2012). Kiamycin, a unique cytotoxic angucyclinone derivative from a marine Streptomyces sp. Mar. Drugs 10, 551-558. doi: 10.3390/md 10030551

Yang, S., Sun, W., Tang, C., Jin, L. L., Zhang, F. L., and Li, Z. Y. (2013). Phylogenetic diversity of Actinobacteria associated with the soft coral Alcyonium graclimum and the stony coral Tubastraea coccinea collected from the East China Sea. Microb. Ecol. 66, 189-199. doi: 10.1007/s00248-0130205-4

Yi, H., Schumann, P., Sohn, K., and Chun, J. (2004). Serinicoccus marinus gen. nov., sp. nov., a novel actinomycete with L-ornithine and L-serine in the peptidoglycan. Int. J. Syst. Evol. Microbiol. 54, 1585-1589. doi: 10.1099/ijs.0.03036-0

Zhang, D. F., Pan, H. Q., He, J., Zhang, X. M., Zhang, Y. G., Klenk, H. P., et al. (2013a). Description of Streptomonospora sediminis sp. nov., and Streptomonospora nanhaiensis sp. nov., and reclassification of Nocardiopsis arabia Hozzein \& Goodfellow 2008 as Streptomonospora arabica comb. nov., and emended description of the genus Streptomonospora. Int. J. Syst. Evol. Microbiol. 63, 4447-4455. doi: 10.1099/ijs.0.052704-0

Zhang, G., Cao, T., Ying, J., Yang, Y., and Ma, L. (2014). Diversity and novelty of actinobacteria in Arctic marine sediments. Antonie Van Leeuwenhoek 105, 743-754. doi: 10.1007/s10482-014-0130-7

Zhang, H., Lee, Y., Zhang, W., and Lee, H. (2006). Culturable actinobacteria from the marine sponge Hymeniacidon perleve: isolation and phylogenetic diversity by 16 S rRNA gene-RFLP analysis. Antonie Van Leeuwenhoek 90, 159-169. doi: 10.1007/s10482-006-9070-1

Zhang, W., Xue, S., Zhao, Q., Zhang, X., Li, J., Jin, M., et al. (2003). Biopotentials of marine sponges from China oceans: past and future. Biomol. Eng. 20, 413-419. doi: 10.1016/S1389-0344(03)00066-2

Zhang, X. Y., He, F., Wang, G. H., Bao, J., Xu, X. Y., and Qi, S. H. (2013b). Diversity and antibacterial activity of culturable actinobacteria isolated from five species of the South China Sea gorgonian corals. World J. Microbiol. Biotechnol. 29, 1107-1116. doi: 10.1007/s11274-013-1279-3

Zhu, H. H., Jiang, S. M., Yao, Q., Wang, Y. H., Chen, M. B., Chen, Y. L., et al. (2011) Streptomyces fenghuangensis sp. nov., isolated from seawater. Int. J. Syst. Evol. Microbiol. 61, 2811-2815. doi: 10.1099/ijs.0.029280-0

Conflict of Interest Statement: The authors declare that the research was conducted in the absence of any commercial or financial relationships that could be construed as a potential conflict of interest.

Copyright (C) 2015 Sun, Zhang, He, Karthik and Li. This is an open-access article distributed under the terms of the Creative Commons Attribution License (CC BY). The use, distribution or reproduction in other forums is permitted, provided the original author(s) or licensor are credited and that the original publication in this journal is cited, in accordance with accepted academic practice. No use, distribution or reproduction is permitted which does not comply with these terms. 